Research Article

\title{
Rail Corrugation Characteristics of Cologne Egg Fastener Section in Small Radius Curve
}

\author{
Zhiqiang Wang $\mathbb{D}^{1,2}$ Zhenyu Lei $\left.{ }^{1}\right)^{1,2}$ Yang Zhao, ${ }^{1,2}$ and Yao $\mathrm{Xu}^{1,2}$ \\ ${ }^{1}$ Institute of Rail Transit, Tongji University, Shanghai 201804, China \\ ${ }^{2}$ Shanghai Key Laboratory of Rail Infrastructure Durability and System Safety, Tongji University, Shanghai 201804, China
}

Correspondence should be addressed to Zhiqiang Wang; 1733359@tongji.edu.cn and Zhenyu Lei; leizhenyu@tongji.edu.cn

Received 3 October 2019; Revised 2 April 2020; Accepted 18 May 2020; Published 11 June 2020

Academic Editor: Nicola Nisticò

Copyright (c) 2020 Zhiqiang Wang et al. This is an open access article distributed under the Creative Commons Attribution License, which permits unrestricted use, distribution, and reproduction in any medium, provided the original work is properly cited.

\begin{abstract}
By analyzing the measured data of rail corrugation in a small radius curve track with Cologne fasteners, the typical passing frequencies of corrugation were obtained. Then, according to actual line conditions, the vehicle-track coupled model and rail material friction and wear model were established and simulated, and rail corrugation characteristics of the curved section were studied. The results show that the variation amplitude of creep force on the inside of a guiding wheelset is large, and it coincides with that of the saturated creep force partially and the coincident part appears periodically. The variation amplitude of creep force on the outside of the guiding wheelset is small, and it is approximately equal to that of the saturated creep force. In addition, the variation range of the wear depth curve on inner rail is mainly changing from $0 \mu \mathrm{m}$ to $0.0014 \mu \mathrm{m}$, showing periodic wavy wear, and when the creep force is equal to the saturated creep force, the wear depth reaches the peak. The variation range of the wear depth curve on outer rail is mainly changing from $0.0005 \mu \mathrm{m}$ to $0.0008 \mu \mathrm{m}$, showing uniform wear. Combined with the predicted profile of rail wear, it can be seen that the inner rail mainly suffers from corrugation on the top of rail and the outer rail mainly suffers from uniform wear on the side, which results in serious corrugation on inner rail and slight corrugation on outer rail. The frequency characteristics analysis of wear shows that the inner rail wear has characteristic frequencies similar to the passing frequencies. Modal analysis results show that the vibration of inner rail at the characteristic frequencies is greater than that of outer rail, which lead to the corrugation of the corresponding frequencies more easily. The wear growth rates at the characteristic frequencies are relatively large, which indicates that the wear at the corresponding frequencies will continue to develop and eventually form corrugation.
\end{abstract}

\section{Introduction}

Corrugation is a kind of defect on rail heads, which is characterized by periodic irregularity of rail surface, and its shape is similar to that of wave. Corrugation occurs to varying degrees in metro systems all over the world, especially in small radius curve sections [1-4]. The wavelength of corrugation is generally between $20 \mathrm{~mm}$ and $300 \mathrm{~mm}$, and the wave depth is not more than $1 \mathrm{~mm}$ [5]. Generally speaking, if the recurrence period of rail corrugation in a small radius curve section is not less than half a year, it can be regarded as normal corrugation. If rail corrugation occurs on a large radius curve section or straight line and the recurrence period is less than four months, it is considered as abnormal corrugation [6]. Rail corrugation has a serious negative impact on vehicles, tracks, and surrounding environment.

Since rail corrugation was first discovered in 1895 , people have observed and investigated corrugation for more than 100 years. During this period, a lot of results on theoretical models, indoor tests, and field tests of corrugation had been presented. Table 1 lists a part of researchers and their corresponding research results.

The existing results on corrugation are mainly based on time domain (nonlinear) and frequency domain (linear). Based on the nonlinear vehicle-track interaction, the nonlinear factors were introduced into the calculation model of rail corrugation for the first time by Igeland and Ilias [12]. 
TABLE 1: History of corrugation investigations.

\begin{tabular}{|c|c|}
\hline Refs & Results and conclusions \\
\hline Johnson and Gray [7] & Rail corrugation induced by wheel-rail contact resonance \\
\hline Grassie et al. [8-10] & Wavelength fixed mechanism and damage mechanism, frequency fixed mechanism \\
\hline Wang et al. [11] & $\begin{array}{c}\text { When the line was not smooth, the torsional vibration of wheelset would lead to the formation of } \\
\text { corrugation }\end{array}$ \\
\hline Igeland and Ilias [12] & For the first time, nonlinear factors were introduced into the model of corrugation calculation \\
\hline Valdivia et al. [13] & $\begin{array}{c}\text { Corrugation was caused by the interaction of wheel-rail dynamics, wheel-rail rolling contact, and material } \\
\text { mechanics }\end{array}$ \\
\hline Dinna et al. [14] & $\begin{array}{c}\text { Corrugation was caused by actions of periodic track impedance and high creepage when vehicle passes } \\
\text { curve }\end{array}$ \\
\hline Nielsen [15] & Wheel-rail rolling contact could filter the rail surface roughness \\
\hline Jin et al. [ & Based on wheel-rail dynamics, the calculation model of wear type corrugation was established and verified \\
\hline Wu and Thompson [17] & $\begin{array}{l}\text { Based on the two-dimensional unsteady contact model and wear model, the locomotive dynamic model } \\
\text { was established in the frequency domain }\end{array}$ \\
\hline Wen [18] & $\begin{array}{l}\text { Combining the vertical coupled dynamics of vehicle-rail, unsteady rolling finite element model and two- } \\
\text { dimensional rolling contact model of cater, the calculation model of corrugation of plastic flow pattern was } \\
\text { established }\end{array}$ \\
\hline $\mathrm{Wu}$ & Fractal description of rail corrugation was established \\
\hline Zhang et al. [20] & ts for corrugation developed on Egg fastener track \\
\hline$[21]$ & $\begin{array}{l}\text { Using field observations, experiments and numerical study were conducted to investigate the occurrence } \\
\text { mechanism of corrugation }\end{array}$ \\
\hline Cui & Corrugation was caused by friction, self-excited vibration between wheels and rails \\
\hline al. [4] & Formation mechanism and mitigation measures of short pitch corrugation \\
\hline
\end{tabular}

Nielsen [23] used the nonlinear rail wear model to study the generation of corrugation on straight lines, and validated the model with the field test on Dutch railways. Sun et al. [24, 25] proposed a simplified feedback model of corrugation including the delay of wheel transfer time. Stability analysis was used to determine the growth of corrugation when multiple wheelsets passed. Sheng et al. [26] used an unsteady two-dimensional method and a three-dimensional FASTSIM model to calculate the wheel-rail tangential creep force and predicted the development trend of corrugation through repeated loading on wheelsets. Chen et al. [27] founded the finite element time domain model of the wheelset passing sharp radius curve. The simulation results showed that the wheel-rail self-induced vibration is an important cause of curve corrugation. Tassilly and Vincent [28] studied the transfer function among the wheel, rail initial roughness, and wear rate by using the linear model of corrugation. It was illustrated that the increase of rail corrugation in some frequency bands was mainly due to the combined effect of creepage between wheels and rails, wheel-rail parameters, and initial irregularity of rail surface. Based on the previous linear theoretical model, Müller [29] assumed that the wheel is in a static state, and the rail surface irregularity was loaded between wheels and rails to simulate the dynamic characteristics of wheels passing track. Li [30] used the finite element model to analyze the relationship between passing frequencies of corrugation and natural frequencies of track structure. However, subject to the complexity of interaction between wheels and rails and the influence of various factors, it is still an open problem on building convincing explanations for the formation and evolution mechanisms of corrugation.

Based on the measured data of corrugation obtained from our experiments, a serious corrugation phenomenon appears on the curve section of the Cologne Egg fastener track, as an unusually severe one in comparison with the ones on the straight line. More generally, the inner rail of the curve track with a radius less than $350 \mathrm{~m}$ produces corrugation of almost $100 \%$, while outer rail seldom produces corrugation or has slight corrugation. In this paper, the corrugation characteristics of inner and outer rails in the small radius curve section of the Cologne fastener track are investigated by both computational simulations and analysis of the measured data. Then, the vehicle-track coupled model and the rail material friction and wear model are established, and the wheel-rail creep characteristics are analyzed in time domain. Combined with the prediction profile of rail wear, the phenomena of serious corrugation on inner rail and slight corrugation on outer rail in the small radius curve section are explained. Finally, by using the frequency domain method, the development characteristics of wear are analyzed by using wear growth rate and the wear growth rates at the characteristic frequencies to develop and eventually form corrugation are discussed.

\section{Characteristics of Measured Corrugation}

The operating vehicle in the corrugation section is a metro type A vehicle. The curve radius is $350 \mathrm{~m}$ and foundation under rails is the integral track bed structure. The irregularity of measured corrugation (inner rail) and one-third octave wavelength spectrum of irregularity grades are shown in Figures 1(a) and 1(b). The characteristic wavelengths shown in Figure 1(b) are $20 \mathrm{~mm}, 31.5 \mathrm{~mm}, 63 \sim 80 \mathrm{~mm}$. The running speed of the vehicle is about $40 \mathrm{~km} / \mathrm{h}$, and the passing frequency $f$ corresponding to the specific wavelength $\lambda$ can be obtained according to the following equation: 


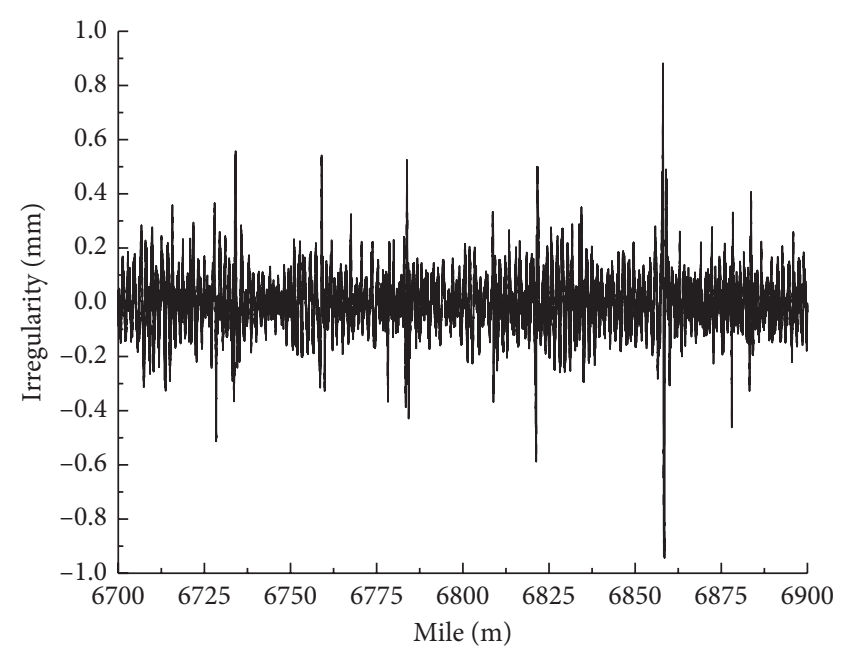

(a)

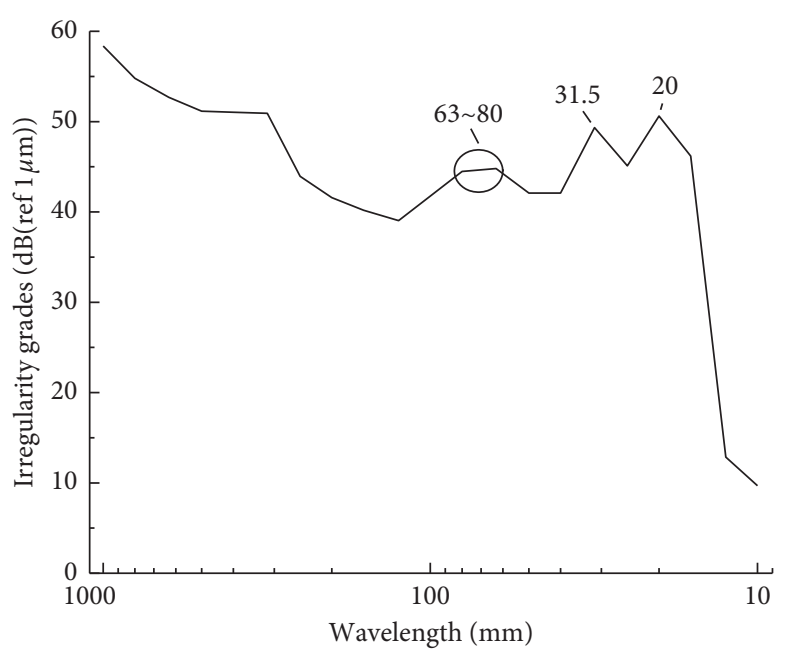

(b)

FIgURE 1: Measured corrugation. (a) Rail surface irregularity. (b) One-third octave wavelength spectrum of irregularity grades.

$$
f=\frac{v}{\lambda}
$$

where $v$ is the speed. The passing frequencies are

$$
\begin{aligned}
& f_{1}=\frac{40 \times 1000}{3.6 \times 20}=556 \mathrm{~Hz}, \\
& f_{2}=\frac{40 \times 1000}{3.6 \times 31.5}=353 \mathrm{~Hz}, \\
& f_{3}=\frac{40 \times 1000}{3.6 \times(63 \sim 80)}=139 \sim 176 \mathrm{~Hz} .
\end{aligned}
$$

Further, the field measurement is carried out as shown in Figure 2; the wavelength ranges of corrugation are about $20 \sim 35 \mathrm{~mm}$ and $55 \sim 85 \mathrm{~mm}$, which are close to that listed in Figure 1(b), indicating that the numerical calculation result is correct.

\section{Vehicle-Track Space Coupled Model}

3.1. Vehicle Model. The main parameters of a metro type A vehicle are shown in Table 2. The software UM (Universal Mechanism) is used to build the vehicle model of a multibody system, referring to the literature [31] for details.

3.2. Track Model. The track model is a flexible track model and parameter values of the track structure are shown in Table 3. The detailed establishment process of the track model is shown in the literature [31].

3.3. Wheel-Rail Contact Model. The wheel-rail contact model adopted the Kik-Piotrowski contact model, which has the characteristics of fast calculation speed and high reliability [32]. The vehicle-track space coupled model diagram is shown in Figure 3.

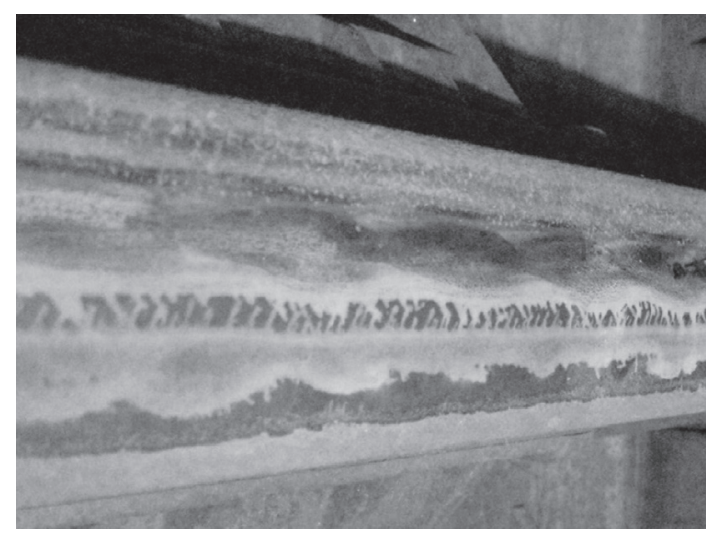

Figure 2: Picture of field measured corrugation.

TABLE 2: Vehicle parameters.

\begin{tabular}{lcc}
\hline Parameters & Values & units \\
\hline Wheelset mass & 1420 & $\mathrm{~kg}$ \\
Bogie frame mass (excludes wheelsets) & 4420 & $\mathrm{~kg}$ \\
Vehicle mass & 26040 & $\mathrm{~kg}$ \\
Primary spring vertical stiffness & $1.3 \times 10^{6}$ & $\mathrm{~N} / \mathrm{m}$ \\
Primary spring transverse stiffness & 547000 & $\mathrm{~N} / \mathrm{m}$ \\
Primary spring longitudinal stiffness & 547000 & $\mathrm{~N} / \mathrm{m}$ \\
Primary spring vertical damping & 2400 & $(\mathrm{Ns}) / \mathrm{m}$ \\
Secondary spring vertical stiffness & 270000 & $\mathrm{~N} / \mathrm{m}$ \\
Secondary spring transverse stiffness & 115000 & $\mathrm{~N} / \mathrm{m}$ \\
Secondary spring longitudinal stiffness & 115000 & $\mathrm{~N} / \mathrm{m}$ \\
Secondary spring vertical damping & 23000 & $(\mathrm{Ns}) / \mathrm{m}$ \\
Length of vehicle & 22.0 & $\mathrm{~m}$ \\
Width of vehicle & 3.0 & $\mathrm{~m}$ \\
Wheel-base bogie & 2.5 & $\mathrm{~m}$ \\
Length between bogie pivot centers & 15.7 & $\mathrm{~m}$ \\
\hline
\end{tabular}

\section{Wear Calculation Model}

The friction and wear calculation model based on friction work theory is used to calculate rail surface wear. The 
TABLE 3: Track structure parameters.

\begin{tabular}{lcc}
\hline Parameters & Values & units \\
\hline Rail elastic modulus & $2.059 \times 10^{11}$ & $\mathrm{~Pa}$ \\
Rail Poisson's ratio & 0.3 & - \\
Rail density & 7800 & $\mathrm{~kg} / \mathrm{m}^{3}$ \\
Friction coefficient & -35 & $\mathrm{MN} / \mathrm{m}$ \\
Vertical stiffness of fasteners & 12.07 & $\mathrm{MN} / \mathrm{m}$ \\
Longitudinal stiffness of fasteners & 7.58 & $\mathrm{MN} / \mathrm{m}$ \\
Transverse stiffness of fasteners & 7.58 & $\mathrm{Ns} / \mathrm{m}$ \\
Vertical damping of fasteners & 1361.12 & $\mathrm{Ns} / \mathrm{m}$ \\
Longitudinal damping of fasteners & 974.27 & $\mathrm{Ns} / \mathrm{m}$ \\
Transverse damping of fasteners & 974.27 & $\mathrm{~m}$ \\
Fastener spacing & 0.6 & $\mathrm{~Pa}$ \\
Slab elastic modulus & $3.25 \times 10^{10}$ & - \\
Slab Poisson's ratio & 0.24 & $\mathrm{~kg} / \mathrm{m}^{3}$ \\
Slab density & 2400 & $\mathrm{~N} / \mathrm{m}$ \\
Support stiffness of foundation & $1.7 \times 10^{8}$ & $\mathrm{Ns} / \mathrm{m}$ \\
Support damping of foundation & $3.1 \times 10^{4}$ & \\
\hline
\end{tabular}

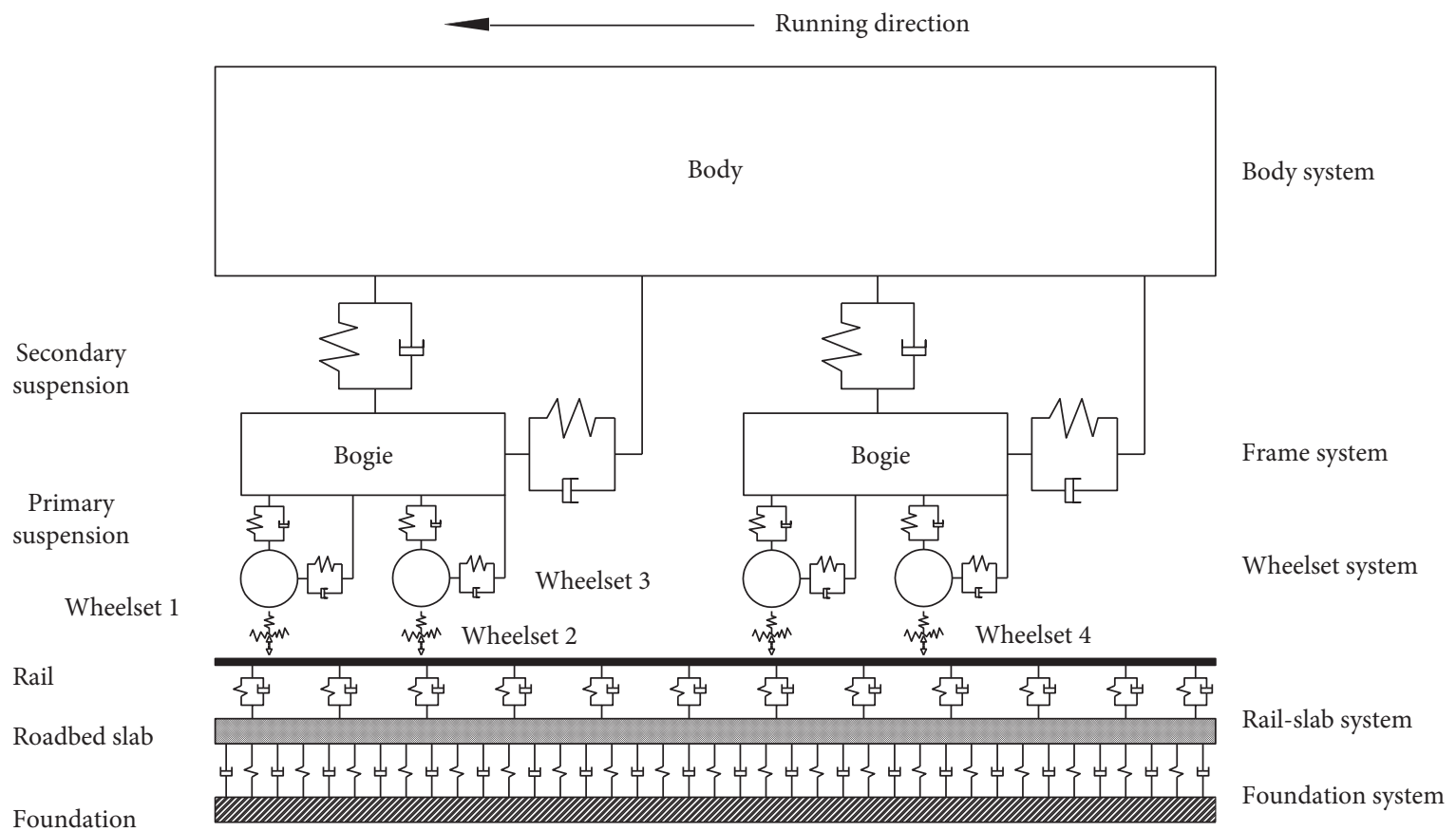

FIGURE 3: Schematic diagram of vehicle-track model.

model can consider the effect of spin creepage on wear. Assuming that the friction power remains unchanged within a shorter time step $\Delta t$, the equation for calculating friction work $W$ is as follows:

$$
W=P \Delta t
$$

where $P$ is the friction power, which is the sum of the product of creep forces and creepages in all directions, as shown in the following equation:

$$
P=F_{x} \nu_{x}+F_{y} \nu_{y}+M_{z} \varphi .
$$

In the UM software, the simulation can output the friction power in the contact area at any time, calculate the friction work in the corresponding time step, and then calculate the total wear amount at that time.

Considering Archard's wear model, the mathematic model of the rail material wear can be expressed as follows:

$$
\Delta m(x)=K W(x)
$$

where $\Delta m$ is the total wear amount produced at position $x$ and $K$ stands for the wear ratio coefficient, which is $1 \times 10^{-9} \mathrm{~kg} / \mathrm{Nm}$ [30].

After the total wear amount is obtained, the wear depth $d(x)$ of rail surface corresponding to the position at that time can be calculated according to the following equation: 


$$
d(x)=\frac{\Delta m(x)}{A \rho},
$$

where $A$ represents the area of contact zone and $\rho$ is the density of rail material, taking $7800 \mathrm{~kg} / \mathrm{m}^{3}$.

In the abovementioned vehicle-track model, the four wheels are running on each rail at the same time, and the wear depth corresponding to each wheel is accumulated at the fixed position of the rail so that the wear depth $\Delta D(x)$ under single operation can be expressed as follows:

$$
\Delta D(x)=\sum_{i=1}^{4} d_{i}(x), \quad(i=1,2,3,4),
$$

where $d_{i}(x),(i=1,2,3,4)$ is the wear depth of each wheel (see Figure 3 ) at the fixed rail position. By adding the wear depth $\Delta D(x)$ calculated by the single operation as irregularity to rail surface, a new rail profile $D_{1}(x)$ can be obtained after the single operation:

$$
D_{1}(x)=D(x)+\Delta D(x),
$$

where $D(x)$ is the initial irregularity of rail surface. In what follows, the next wear amount under the influence of previous wear can be obtained by calculating again. Repeating the process, the superimposed wear on rail surface can be obtained for many times. The flow chart of wear superposition calculation is shown in Figure 4.

By using the Fourier transform of rail profile $D_{n}(x)$ after $n$ times operation, the corresponding rail profile amplitude $D_{n f}(i \omega)$ in frequency domain can be obtained. Compared with the initial irregularity, the wear growth rate $G_{f}$ at frequency $f$ is defined as follows $[33,34]$ :

$$
\begin{aligned}
G_{f} & =\|\left.\frac{D_{n f}(i \omega)}{D_{0}(i \omega)}\right|_{\infty}-1=\sqrt[n]{\max \left|\frac{D_{n f}(i \omega)}{D_{0}(i \omega)}\right|}-1, \\
\left|\frac{D_{n f}(i \omega)}{D_{0}(i \omega)}\right| & ==\alpha^{n} \sqrt{\exp \left[\int_{-\infty}^{+\infty} \ln \left(\frac{\left(\omega_{i}^{2}\left(1-\left(K_{b} K_{c i} / \alpha\right)\right)-\lambda^{2} \omega^{2}\right)+\left(2 \xi_{i} \omega_{i} \lambda \omega\right)^{2}}{\left(\omega_{i}^{2}-\lambda^{2} \omega^{2}\right)^{2}+2\left(\xi_{i} \omega_{i} \lambda \omega\right)^{2}}\right) p(\lambda) \mathrm{d} \lambda\right]^{n}},
\end{aligned}
$$

where $D_{0}(i \omega)$ is the profile amplitude of initial irregularity of rail surface after the Fourier transform, $\alpha$ is the sensitivity of wear, $K_{b}$ is the sensitivity of transverse frictional power induced wear variations to vertical wheel-rail contact deflection variations, $K_{c i}$ is the modal sensitivity of the wheel-rail displacement to a change in longitudinal rail profile, $n$ is the number of wheel passing, $\xi_{i}$ is the modal damping ratio, $\omega_{i}$ is the modal natural frequency, $\omega$ is the angular frequency, for the frequency domain, $\lambda$ is the ratio of the current speed to the mean speed, and $p(\lambda)$ is the probability distribution of $\lambda$. According to equation (9), the wear growth rate $G_{f}$ is a function of frequency $f$. If wear growth rate is positive, it means that rail surface irregularity will continue to develop at the corresponding frequencies. The larger the numerical values, the faster the development, and finally the corrugation will be formed.

\section{Rail Corrugation Characteristics in Curve Section}

5.1. Creep Characteristics. The radius of research curve line is $350 \mathrm{~m}$ and the vehicle speed is $40 \mathrm{~km} / \mathrm{h}$. In order to investigate the wheel-rail creep characteristics, the software UM is used to transform the data of measured corrugation into the irregularity spectrum, and then the generated irregularity spectrum is applied to left and right rail surfaces. The creep force and saturated creep force between guiding wheelsets and rails and corresponding rail wear are simulated and calculated. The data curves are shown in Figures 5 and 6.
The results in Figures 5 and 6 can be summarized as follows:

(1) The variation amplitude of creep force on the inside of the guiding wheelset is large, which is partially coincident with that of the saturated creep force and the coincident part appears periodically. The variation amplitude of creep force on the outside of the guiding wheelset is small, which is approximately equal to that of saturated creep force.

(2) The variation period of the wear depth curve on inner rail is consistent with that of the creep force curve (there is a certain phase difference), and the variation range changes from $0 \mu \mathrm{m}$ to $0.0014 \mu \mathrm{m}$ and shows a periodic wavy wear. When the creep force is equal to the saturated creep force, the wear depth reaches the peak. The variation range of the wear depth curve on outer rail is small, which mainly changes from $0.0005 \mu \mathrm{m}$ to $0.0008 \mu \mathrm{m}$, and implies a kind of uniform wear. Therefore, the inner rail tends to have corrugation while the outer rail tends to have uniform corrugation, which is consistent with the fact that corrugation mostly occurs on inner rail of the small radius curve section.

5.2. Prediction Profile of Rail Wear. In order to further explain the serious corrugation on the inner rail and slight corrugation on the outer rail, the wear position of the rail profile is predicted and analyzed. According to the literature 


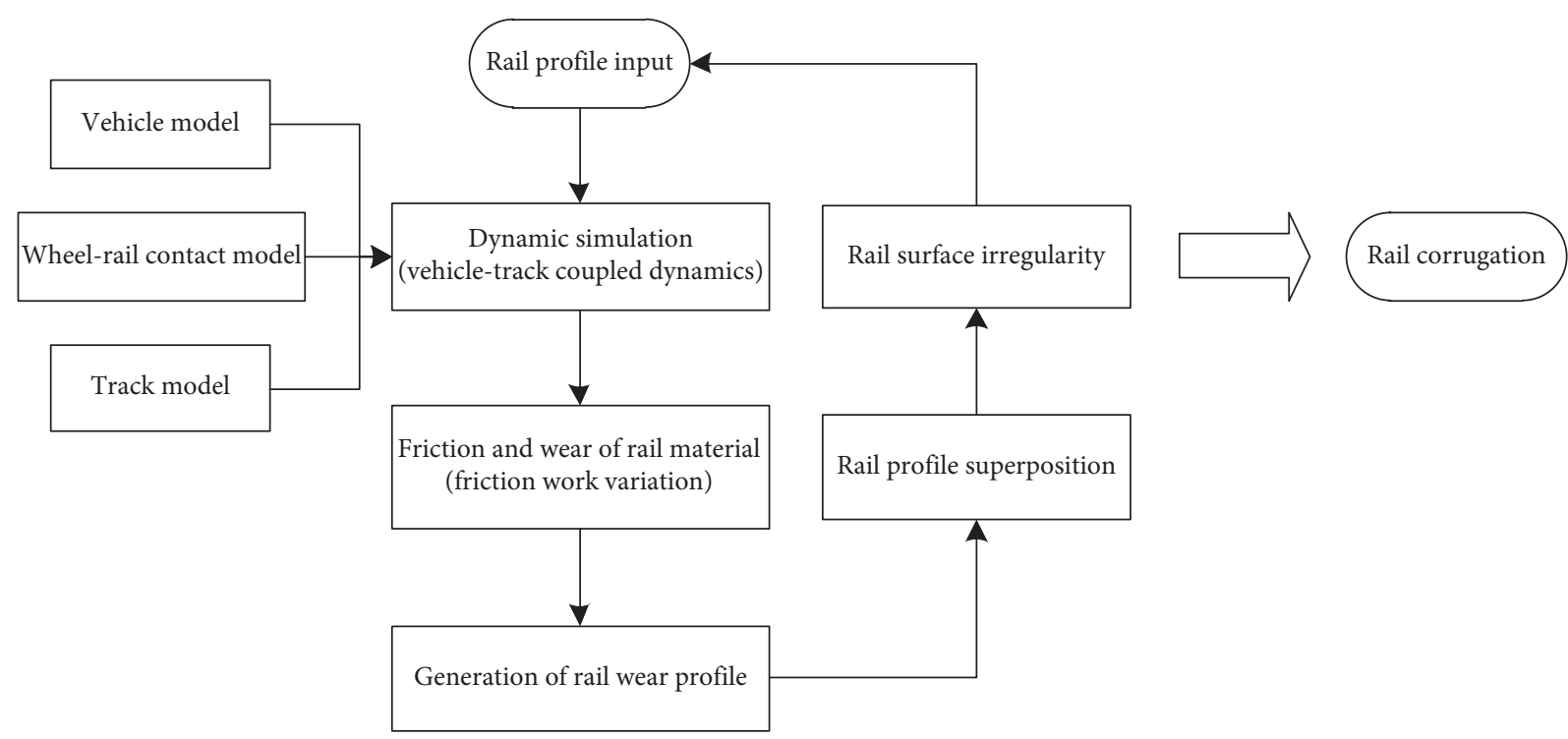

FIgURE 4: Flow chart of wear superposition calculation.

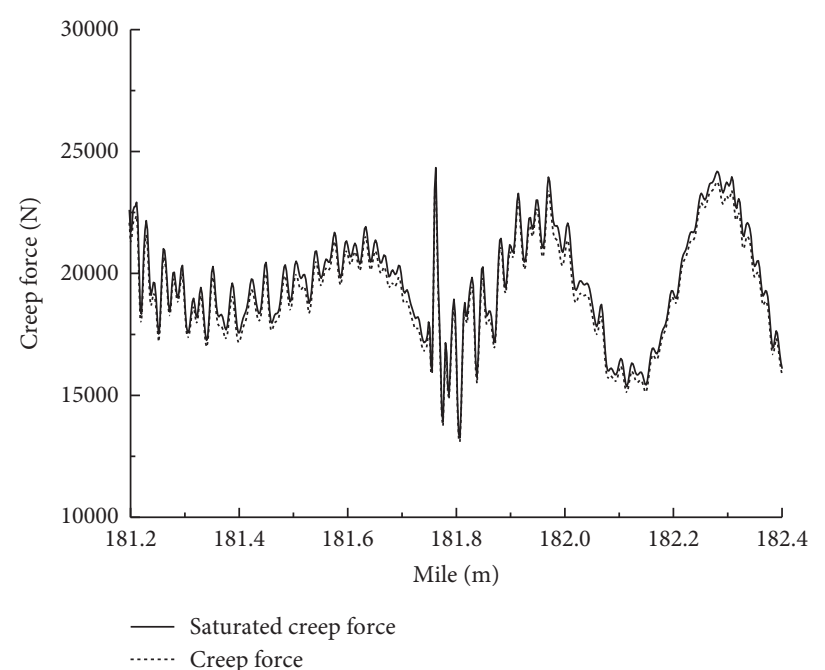

(a)

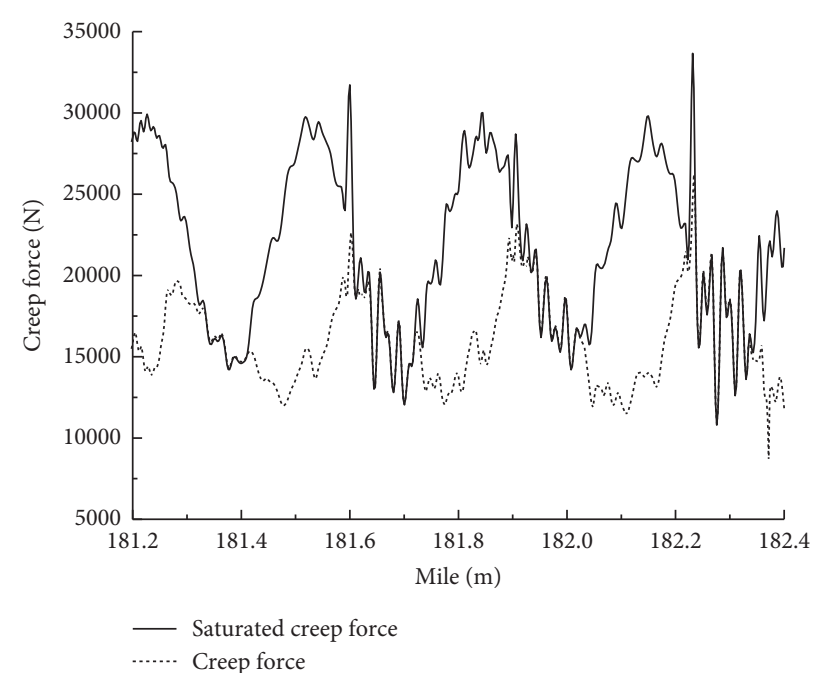

(b)

FIGURE 5: Creep force and saturated creep force. (a) Outer rail. (b) Inner rail.

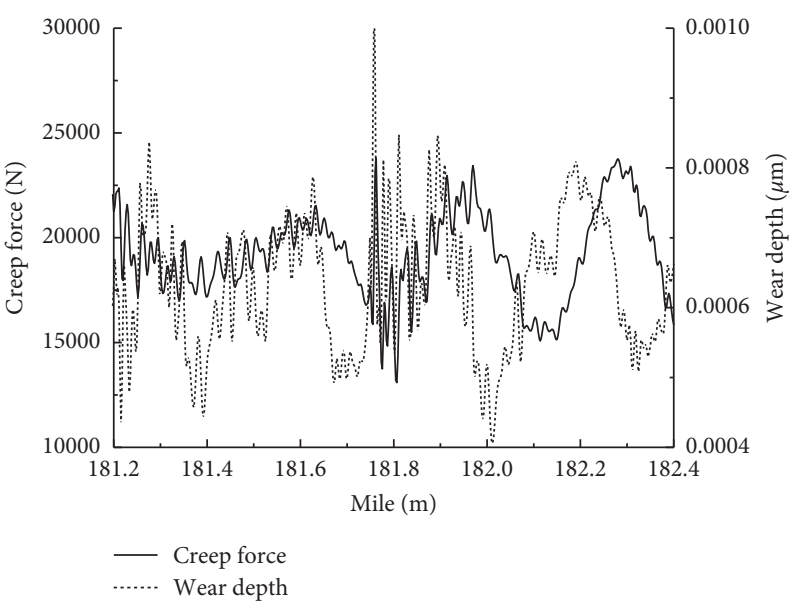

(a)

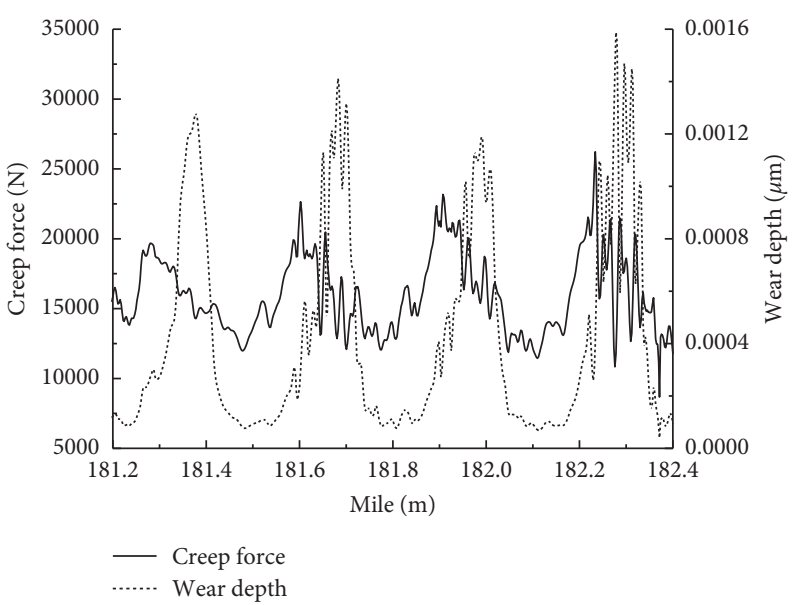

(b)

Figure 6: Creep force and wear depth. (a) Outer rail. (b) Inner rail. 

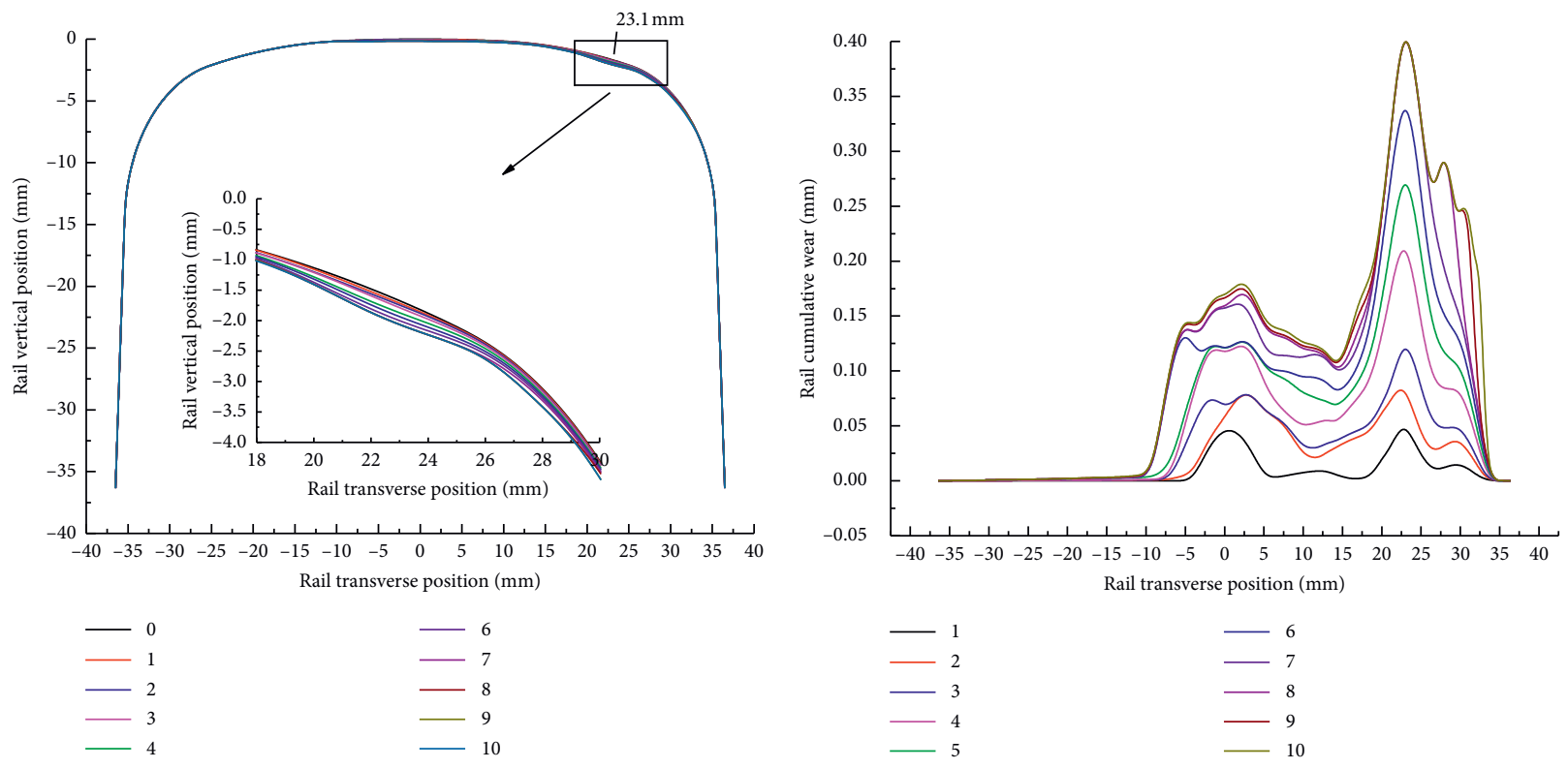

(a)

(b)

Figure 7: Outer rail. (a) Profile contrast diagram. (b) Cumulative wear contrast diagram.

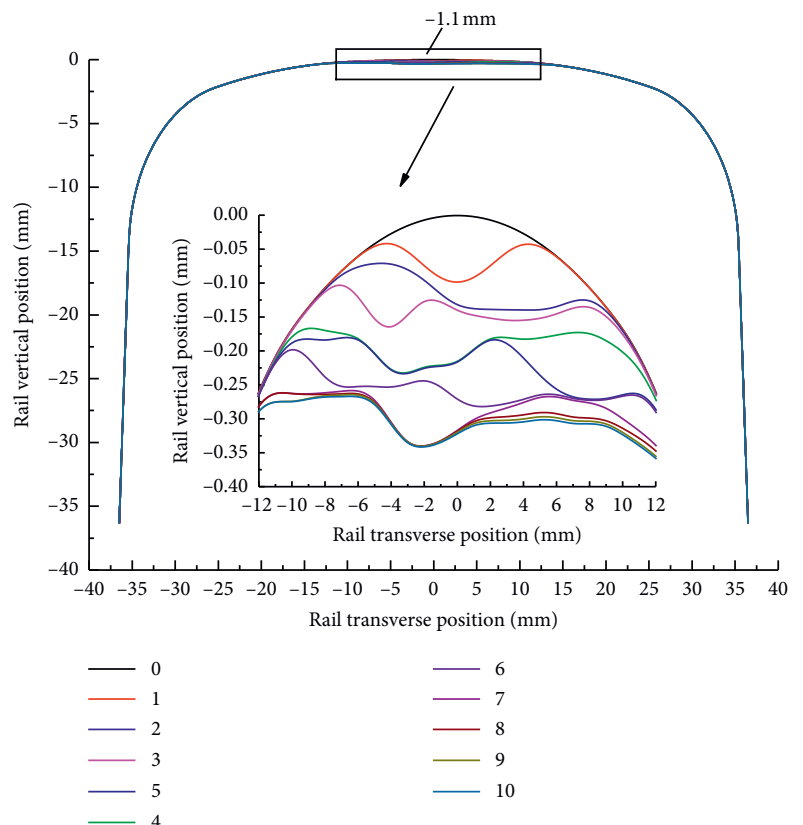

(a)

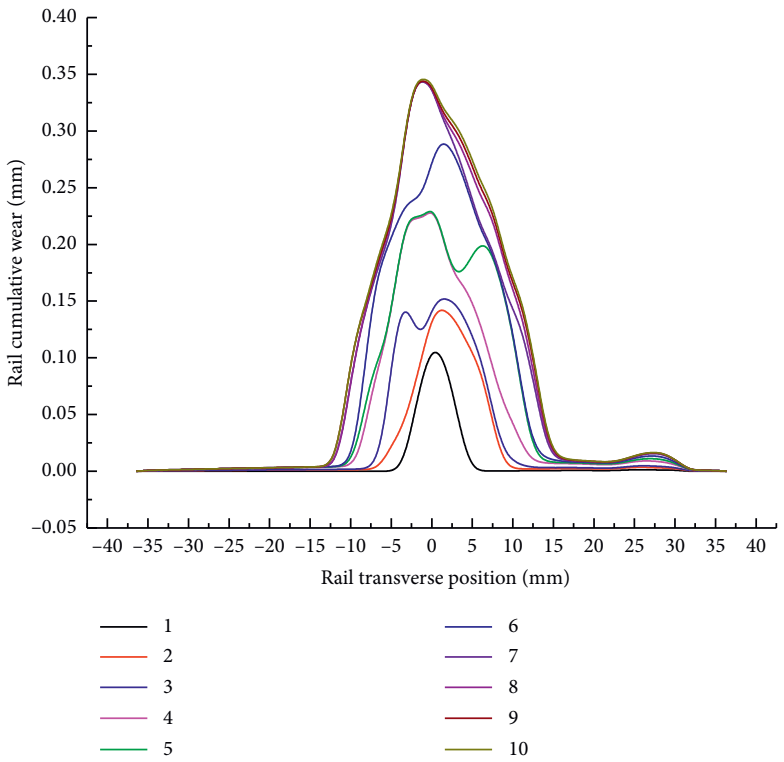

(b)

Figure 8: Inner rail. (a) Profile contrast diagram. (b) Cumulative wear contrast diagram.

[35], the maximum rail wear depth $0.1 \mathrm{~mm}$ is selected as the basis for profile renewal, and the rail profile is smoothed.

Taking the update times as 10 , the profile contrast diagram and cumulative wear contrast diagram of the inner and outer rails are obtained as shown in Figures 7 and 8 .

The analysis results show that the wear of outer rail distributes in the middle of the rail head and shoulder area $(-10 \mathrm{~mm}, 35 \mathrm{~mm})$, and the wear of the shoulder area $(20 \mathrm{~mm}, 30 \mathrm{~mm})$ is large, with the maximum value reaching
$0.40 \mathrm{~mm}$ (rail transverse position $23.1 \mathrm{~mm}$ ). The wear distribution of the inner rail head tread is symmetrical, and the wear of the middle part of the rail head $(-10 \mathrm{~mm}, 10 \mathrm{~mm})$ is relatively large, with the maximum value reaching $0.35 \mathrm{~mm}$ (rail transverse position $-1.1 \mathrm{~mm}$ ).

In order to analyze the reasons for the difference of wears between inner and outer rails, the wheel-rail geometric contact relationship in the simulation process is studied. Since the geometric parameters involved in the 
wheel-rail space geometric contact relationship are in the principle functions of the wheelset transverse displacement and contact angle (angle between wheel-rail contact surface and horizontal surface), several geometric parameters can be simplified to functions of wheelset transverse displacement and contact angle [36] when studying the difference of wear distribution between inner and outer rails. Figure 9 shows the change of wheelset transverse displacement during the operation of vehicle, and Figure 10 shows the change of the corresponding contact angle. When the vehicle is passing on the small radius curve section, the wheelset traverse displacement is large, and it is in the range of $9 \sim 10 \mathrm{~mm}$, and the contact angle changes slightly, approaching zero.

Based on the matching relationship between the LMA wheel tread and $\mathrm{CN} 60$ rail profile, the transient contact solutions of the wheelset passing curve with different transverse displacements and contact angles can be obtained, as shown in Figure 11. The analysis shows that when the wheelset transverse displacement reaches $9 \sim 10 \mathrm{~mm}$ and the contact angle approaches zero, the wheel flange attaches to the rail. Increasing the wheelset transverse displacement will cause the wheel flange to move toward outer rail, resulting in a large outer wheelrail contact angle, which is prone to rail side wear. The inner wheel-rail contact angle is smaller, and wear mainly occurs on the middle part of the rail head. This can also be derived from the wheel-rail contact diagram shown in Figure 12.

Furthermore, combined with the wheel-rail contact patch diagram shown in Figure 13, it can be obtained that the outer wheel-rail contact patch is mainly located in the shoulder area, resulting in large wear in the corresponding area, which is consistent with the wear distribution of outer rail shown in Figure 7. The inner wheel-rail contact patch mainly distributes in the middle part of the rail head, making the wear of the corresponding area large, which is also consistent with the wear distribution of inner rail shown in Figure 8. Therefore, from the angle of wheel-rail geometric contact relationship, the difference of wear distribution between inner and outer rails in a small radius curve can be well explained.

According to the predicted profile of rail wear, the outer rail wear mainly occurs on the rail shoulder, while the inner rail wear mainly occurs on the middle of the rail head. Combining the conclusion in Section 5.1 (the inner rail tends to have corrugation while the outer rail tends to have uniform wear), the inner rail mainly has corrugation on the top of rail, and the outer rail mainly has uniform wear on the side, which results in serious corrugation on inner rail and slight corrugation on outer rail.

5.3. Frequency-Domain Characteristics of Wear Growth. According to the data of measured corrugation in Section 2 , the maximum passing frequency is about $556 \mathrm{~Hz}$, so the frequency range in frequency domain analysis is set to $0 \sim 600 \mathrm{~Hz}$. The circular curve $(R=350 \mathrm{~m})$ with a length of $200 \mathrm{~m}$ is selected for simulation, the measured rail surface

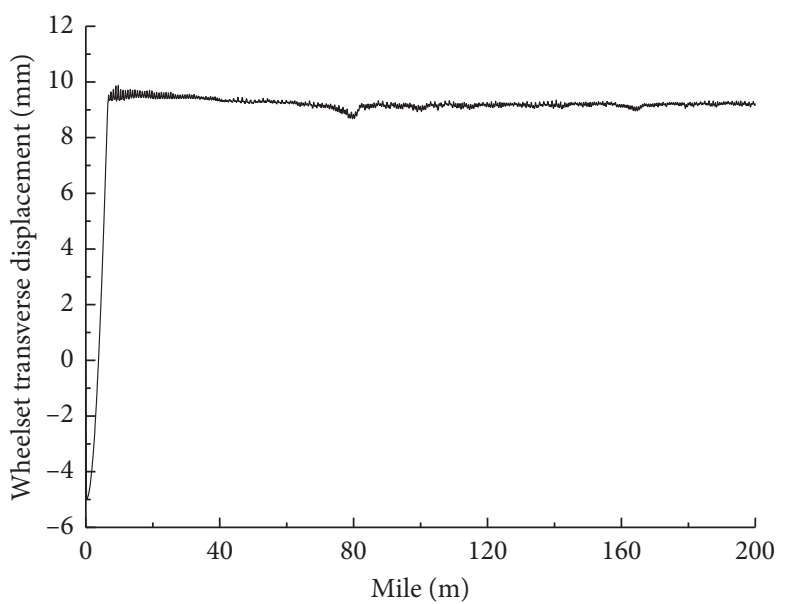

Figure 9: Transverse displacement of the wheelset.

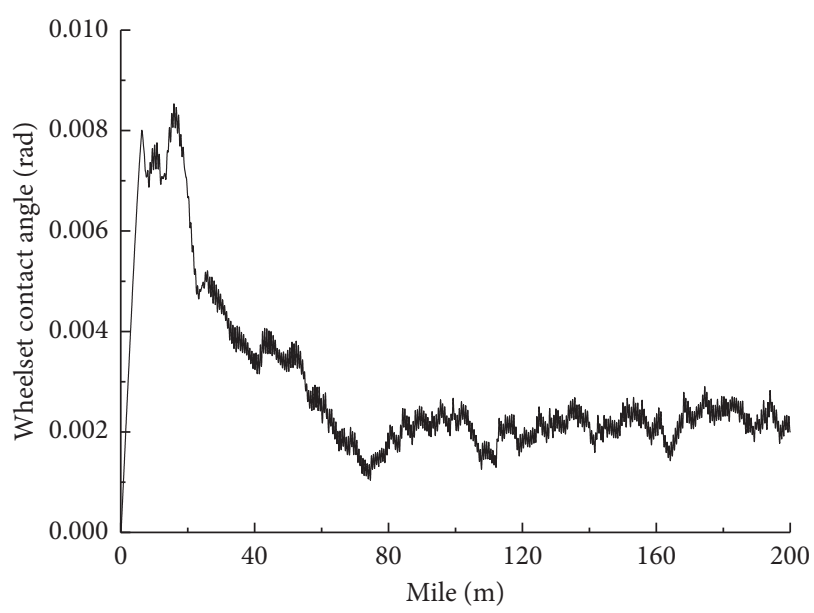

Figure 10: Wheelset contact angle.

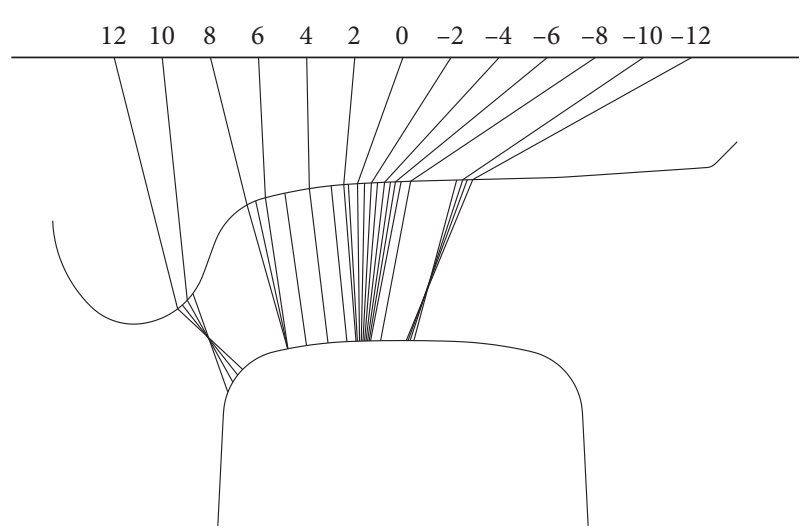

FIgURE 11: Schematic diagram of wheel-rail contact point pairs.

irregularity is taken as the initial irregularity to calculate the wear amount (the additional wear generated by train running, considering 4 wheel runs on a rail) under a single operation, and the characteristic frequencies of rail corrugation (inner rail) can be obtained by the Fourier transform of wear results, as shown in Figure 14. 


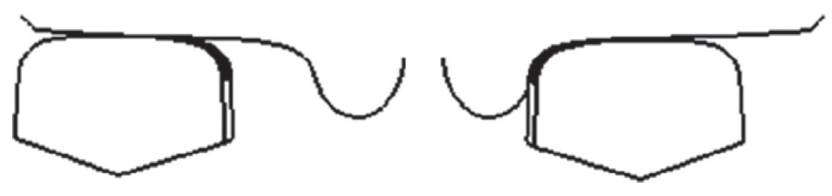

(a)

(b)

FIgURE 12: Wheel-rail contact relationship. (a) Inner rail. (b) Outer rail.

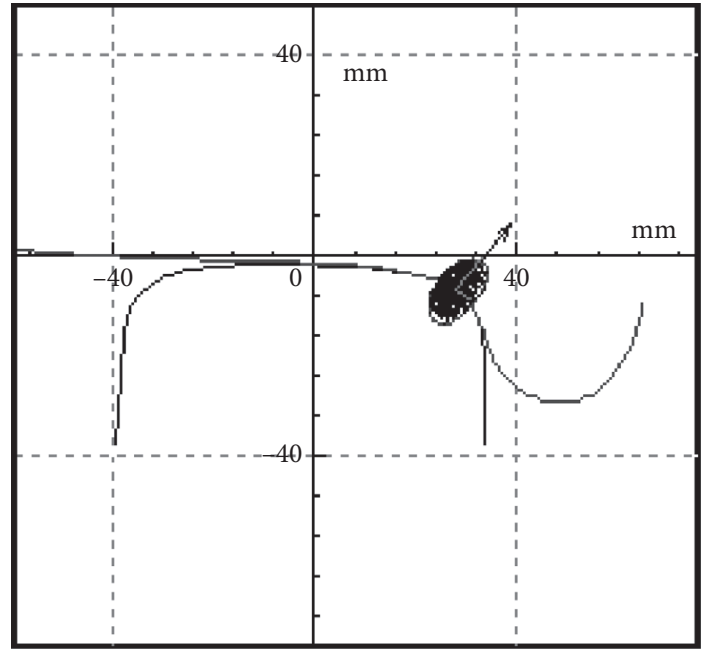

(a)

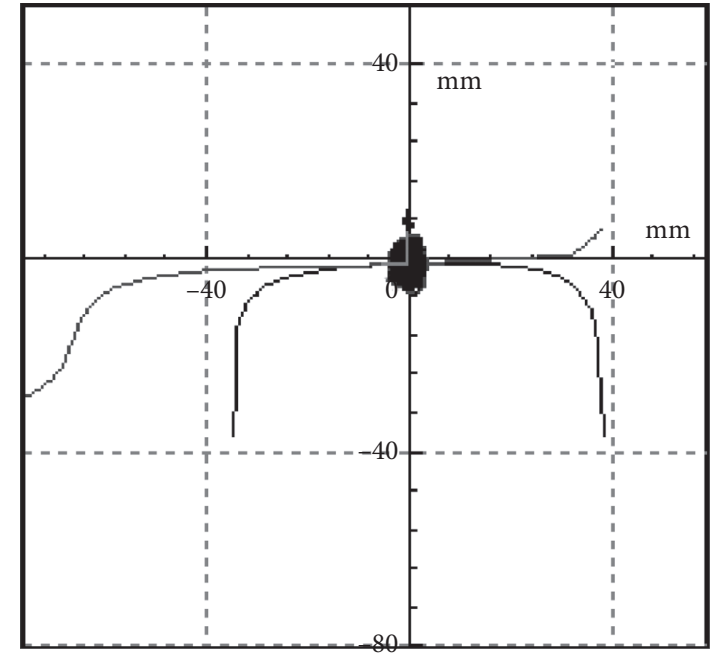

(b)

Figure 13: Contact patch diagram. (a) Outside. (b) Inside.

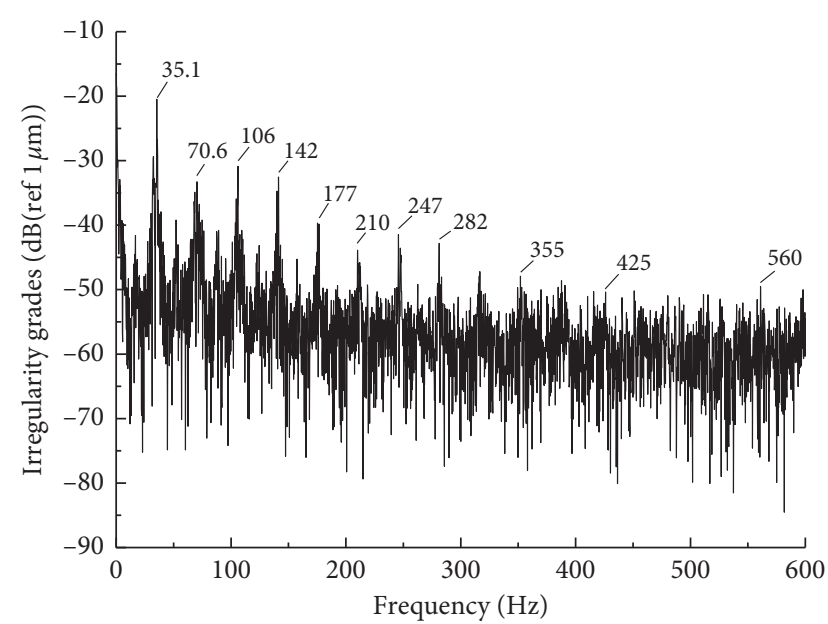

FIGURE 14: Wear grade spectrum.

As can be seen from Figure 14, the basic frequency of characteristic frequencies of rail wear is $35.1 \mathrm{~Hz}$, which is caused by the wheel-rail low frequency impact force P2. When the wheel passes the low joint, weld, corrugation section, or wheel scratch, there will be two impact forces: high-frequency impact force P1 and low-frequency impact force P2. Force P1 is the impact force caused by the prominent surface defects such as joints and wheel flat. The $\mathrm{P} 1$ resonance can be regarded as the vibration caused by the wheel-rail contact deformation between unsprung mass and rail, and its frequency range is $500 \sim 1000 \mathrm{~Hz}$. It has a very short acting time and usually causes damage to the surfaces of wheels and rails. Force P2 is the impact force caused by the inevitable track irregularity and wheel circumferential irregularity. The P2 resonance can be regarded as the vibration of unsprung mass and track as the whole mass on the resilient foundation under rails, and its frequency range is $20 \sim 100 \mathrm{~Hz}$. It has a long acting time, which can be transmitted to the vehicle parts upward and to the slab downward [37, 38]. Besides, it can be seen from Figure 14 that all other arising frequencies are harmonics of the frequency of $35 \mathrm{~Hz}$, which is considered to be caused by the main frequency separation phenomenon of wheel-rail system responses under the wheel rotation effect $[39,40]$. Meanwhile, the inner rail wear contains characteristic frequencies $(142 \mathrm{~Hz}$, $177 \mathrm{~Hz}, 355 \mathrm{~Hz}$, and $560 \mathrm{~Hz}$ ) similar to the passing frequencies of measured corrugation $(139 \sim 176 \mathrm{~Hz}, 353 \mathrm{~Hz}$, and $556 \mathrm{~Hz}$ ).

Due to fixed frequency characteristics of corrugation, the vibration characteristics of the wheelset-track structure are generally considered as the main cause of corrugation occurrence at the specific frequencies. Using the finite element software ABAQUS, the track structure model with fastener spacing $0.6 \mathrm{~m}$, track centerline length $36 \mathrm{~m}$, curve radius $350 \mathrm{~m}$, and wheelset model with a diameter $840 \mathrm{~mm}$ is established, as shown in Figure 15. The wheel tread is the LMA tread and cross-section size of the slab is $2700 \mathrm{~mm} \times 300 \mathrm{~mm}$. 


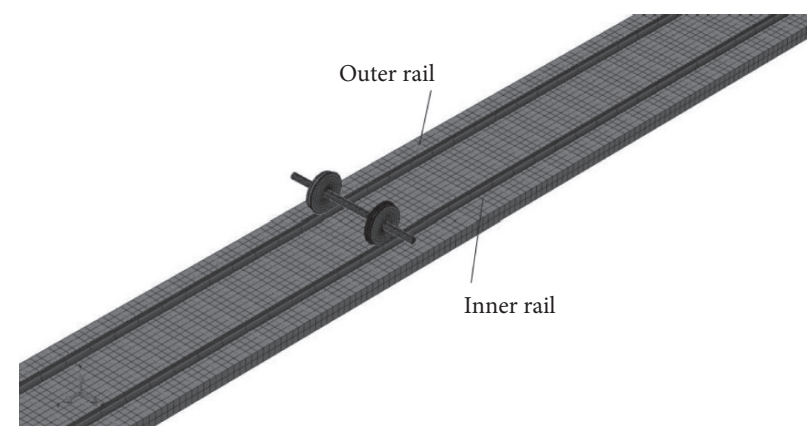

Figure 15: Wheelset-track coupled model.

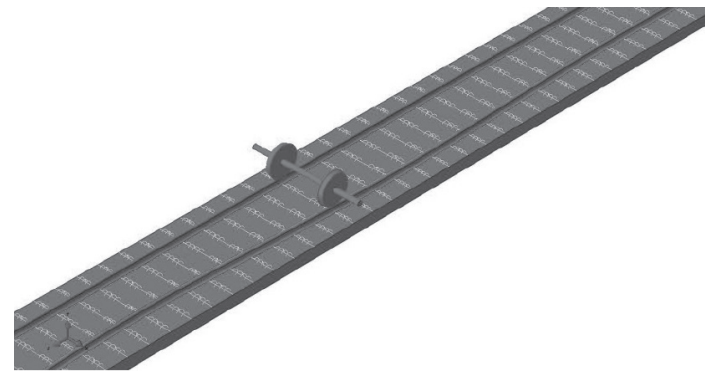

(a)

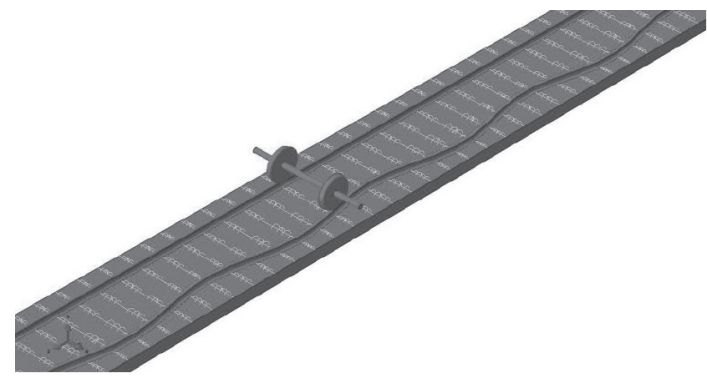

(c)

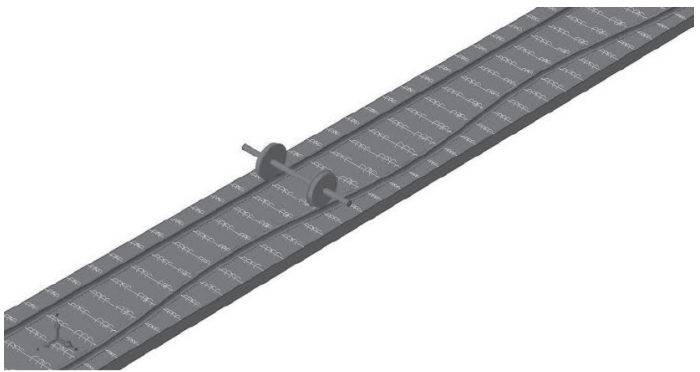

(b)

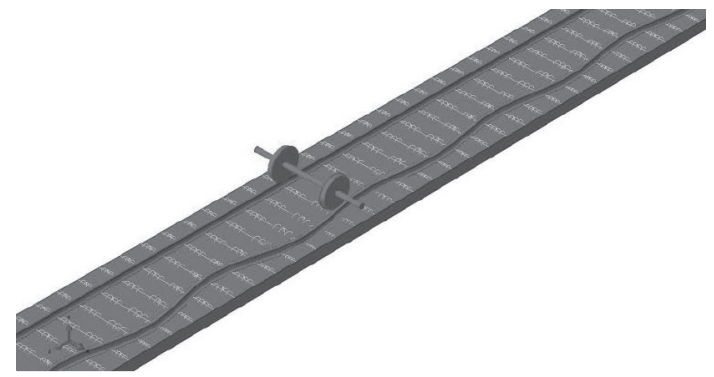

(d)

Figure 16: Mode diagram. (a) $141.7 \mathrm{~Hz}$. (b) $173.8 \mathrm{~Hz}$. (c) $355.1 \mathrm{~Hz}$. (d) $558.9 \mathrm{~Hz}$.

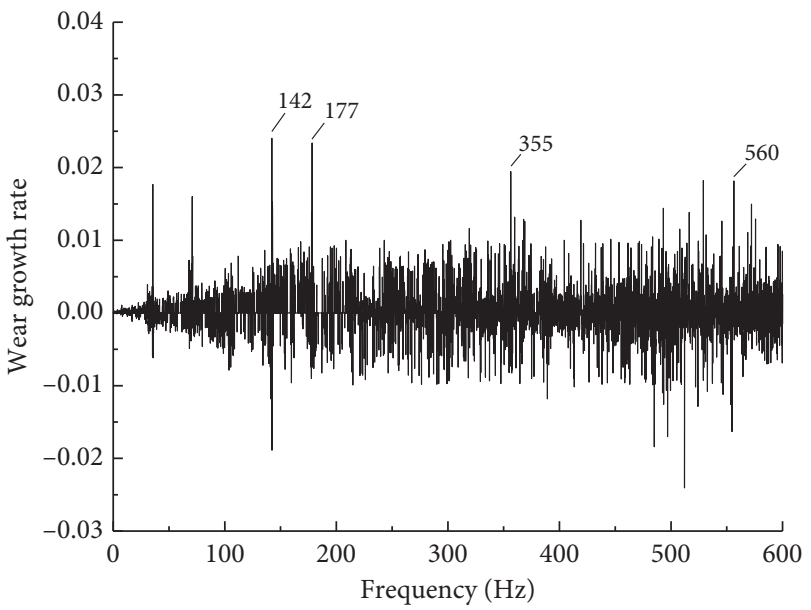

FIgURE 17: Wear growth rate.

Through the modal analysis of the abovementioned model, the natural frequencies of the wheelset-track system and corresponding modes can be obtained, and the modes close to the passing frequencies are shown in Figure 16.

It can be seen from the analysis that the vibration of the inner rail is more violent than that of the outer rail at characteristic frequencies of the wheel-track system, which makes the inner rail more likely to produce the corrugation of corresponding frequencies. This is consistent with the conclusion in Section 5.2 that the inner rail corrugation is serious and the outer rail corrugation is slight.

In order to measure the development level of wear at different frequencies, the wear growth rates at different frequencies of the wear amount (inner rail) relative to the initial irregularity are calculated according to equation (9), as shown in Figure 17.

It can be seen from Figure 17 that the wear growth rates at the characteristic frequencies of $142 \mathrm{~Hz}, 177 \mathrm{~Hz}, 355 \mathrm{~Hz}$, and $560 \mathrm{~Hz}$ are relatively high, and these frequencies are similar to the passing frequencies. This indicates that the wear of corresponding frequencies will continue to develop and finally form corrugation. 


\section{Conclusions}

Based on the measured data in the practical work conditions, the vehicle-track model and the rail material friction and the wear model are built. Further, corrugation characteristics of the Cologne Egg fastener track in the small radius curve are investigated. The following conclusions can be drawn:

(1) The variation amplitude of creep force on the inside of the guiding wheelset is large, which is partially coincident with that of the saturated creep force and the coincident part appears periodically. The variation amplitude of creep force on the outside of the guiding wheelset is small, which is approximately equal to that of the saturated creep force. In addition, the variation period of the wear depth curve on inner rail is consistent with that of the creep force curve (there is a certain phase difference), the variation range is mainly changing from $0 \mu \mathrm{m}$ to $0.0014 \mu \mathrm{m}$, showing periodic wavy wear, and when the creep force is equal to the saturated creep force, the wear depth reaches the peak. The variation range of the wear depth curve on outer rail is small, mainly changing from $0.0005 \mu \mathrm{m}$ to $0.0008 \mu \mathrm{m}$, showing uniform wear.

(2) Combining with the prediction profile of rail wear, it can be seen that side wear mainly occurs on the outer rail, while the corrugation tends to occur on inner rail, which results in serious corrugation on inner rail and slight corrugation on outer rail.

(3) The inner rail wear in the small radius curve contains the characteristic frequencies $(142 \mathrm{~Hz}$, $177 \mathrm{~Hz}, 355 \mathrm{~Hz}$, and $560 \mathrm{~Hz}$ ) similar to the passing frequencies $(139 \sim 176 \mathrm{~Hz}, 353 \mathrm{~Hz}$, and $556 \mathrm{~Hz})$. The simulated results of modal analysis show that the vibration of inner rail is more violent than that of outer rail at the characteristic frequencies of the wheel-track system, which makes inner rail more likely to produce corrugation of corresponding frequencies. The wear growth rates at characteristic frequencies are relatively high, which indicates that the wear at corresponding frequencies will continue to develop and eventually form corrugation.

\section{Data Availability}

The data used to support the findings of this study are available from the corresponding author upon request.

\section{Conflicts of Interest}

The authors declare that they have no conflicts of interest.

\section{Acknowledgments}

This work was supported by the National Natural Science Foundation of China (Grant no. 11772230).

\section{References}

[1] E. Tassilly and N. Vincent, "Rail corrugations: analytical model and field tests," Wear, vol. 144, no. 1-2, pp. 163-178, 1991.

[2] P. T. Torstensson and J. C. O. Nielsen, "Monitoring of rail corrugation growth due to irregular wear on a railway metro curve," Wear, vol. 267, no. 1-4, pp. 556-561, 2009.

[3] H. Xiao, S. Yang, H. Wang, and S. X. Wu, "Initiation and development of rail corrugation based on track vibration in metro systems," Proceedings of the Institution of Mechanical Engineers, Part F: Journal of Rail and Rapid Transit, vol. 232, no. 9, pp. 2228-2243, 2018.

[4] G. Fang, Y. Wang, Z. Peng, and T. Wu, "Theoretical investigation into the formation mechanism and mitigation measures of short pitch rail corrugation in resilient tracks of metros," Proceedings of the Institution of Mechanical Engineers, Part F: Journal of Rail and Rapid Transit, vol. 232, no. 9, pp. 2260-2271, 2018.

[5] L. Cao, Y. D. Xu, Y. Zhou et al., "Characteristics of rail corrugation in urban mass transit," Urban Mass Transit, vol. 13, pp. 46-52, 2010.

[6] J. Ren, J. J. Sun, P. Chen, and W. Jin, "Rethink about metro design from rail abnormal corrugation research," Urban Rapid Rail Transit, vol. 24, pp. 2-5, 2011.

[7] K. L. Johnson and G. G. Gray, "Development of corrugations on surfaces in rolling contact," Proceedings of the Institution of Mechanical Engineers, vol. 189, no. 1, pp. 567-580, 1975.

[8] S. L. Grassie and J. Kalousek, "Rail corrugation: characteristics, causes and treatments," Proceedings of the Institution of Mechanical Engineers, Part F: Journal of Rail and Rapid Transit, vol. 207, no. 1, pp. 57-68, 1993.

[9] S. L. Grassie, "Rail corrugation: advances in measurement, understanding and treatment," Wear, vol. 258, no. 7-8, pp. 1224-1234, 2005.

[10] S. L. Grassie, "Rail corrugation: characteristics, causes, and treatments," Proceedings of the Institution of Mechanical Engineers, Part F: Journal of Rail and Rapid Transit, vol. 223, no. 6, pp. 581-596, 2009.

[11] P. Wang, X. Y. Liu, and F. G. Wan, "Torsional vibration of wheelsets and curved rail corrugations," Journal of Southwest Jiaotong University, vol. 31, pp. 58-62, 1996.

[12] A. Igeland and H. Ilias, "Rail head corrugation growth predictions based on non-linear high frequency vehicle/track interaction," Wear, vol. 213, no. 1-2, pp. 90-97, 1997.

[13] E. G. Vadillo, J. Tárrago, G. G. Zubiaurre, and C. A. Duque, "Effect of sleeper distance on rail corrugation," Wear, vol. 217, no. 1, pp. 140-145, 1998.

[14] G. Diana, F. Cheli, S. Bruni, and A. Collina, "Experimental and numerical investigation on subway short pitch corrugation," Vehicle System Dynamics, vol. 29, no. 1, pp. 234-245, 1998.

[15] J. B. Nielsen, "Evolution of rail corrugation predicted with a nonlinear wear model," Journal of Sound and Vibration, vol. 227, pp. 915-933, 1999.

[16] X. S. Jin, Z. F. Wen, and K. Y. Wang, "Theoretical model and numerical method of rail corrugation," Journal of Traffic and Transportation Engineering, vol. 5, pp. 15-21, 2005.

[17] T. X. Wu and D. J. Thompson, "An investigation into rail corrugation due to micro-slip under multiple wheel/rail interactions," Wear, vol. 258, no. 7-8, pp. 1115-1125, 2005.

[18] Z. F. Wen, Research on Rail Corrugation, Southwest Jiaotong University, Chengdu, China, 2006. 
[19] Z. Wu, X. Y. Liu, and L. K. Yao, "Fractal description of rail corrugation and its dynamic simulation," Journal of Southwest Jiaotong University, vol. 44, pp. 721-725, 2009.

[20] H. G. Zhang, W. N. Liu, Z. Z. Wu et al., "Causes and treatment for rail corrugation developed on Egg fastening system section of metro line," China Railway Science, vol. 35, pp. 22-28, 2014.

[21] W. Li, H. Wang, Z. Wen et al., "An investigation into the mechanism of metro rail corrugation using experimental and theoretical methods," Proceedings of the Institution of $\mathrm{Me}$ chanical Engineers, Part F: Journal of Rail and Rapid Transit, vol. 230, no. 4, pp. 1025-1039, 2016.

[22] X. Cui, G. Chen, J. Zhao, W. Yan, H. Ouyang, and M. Zhu, "Field investigation and numerical study of the rail corrugation caused by frictional self-excited vibration," Wear, vol. 376-377, pp. 1919-1929, 2017.

[23] J. C. O. Nielsen, "Numerical prediction of rail roughness growth on tangent railway tracks," Journal of Sound and Vibration, vol. 267, no. 3, pp. 537-548, 2003.

[24] Y. Q. Sun and S. Simson, "Wagon-track modelling and parametric study on rail corrugation initiation due to wheel stick-slip process on curved track," Wear, vol. 265, no. 9-10, pp. 1193-1201, 2008.

[25] P. A. Meehan, W. J. T. Daniel, and T. Campey, "Prediction of the growth of wear-type rail corrugation," Wear, vol. 258, no. 7-8, pp. 1001-1013, 2005.

[26] X. Sheng, D. J. Thompson, C. J. C. Jones et al., "Simulations of roughness initiation and growth on railway rails," Journal of Sound and Vibration, vol. 293, no. 3-5, pp. 819-829, 2006.

[27] G. Chen, W. J. Qian, J. L. Mo et al., "A transient dynamics study on wear-type rail corrugation on a tight curve due to the friction-induced self-excited vibration of a wheelset-track system," Journal of Mechanical Engineering, vol. 50, no. 9, pp. 71-76, 2014.

[28] E. Tassilly and N. Vincent, "A linear model for the corrugation of rails," Journal of Sound and Vibration, vol. 150, no. 1, pp. 25-45, 1991.

[29] S. Müller, "A linear wheel-rail model to investigate stability and corrugation on straight track," Wear, vol. 243, pp. 122$132,2000$.

[30] X. Li, Study on the Mechanism of Rail Corrugation on Subway Track, Southwest Jiaotong University, Chengdu, China, 2012.

[31] Z. Lei and Z. Wang, "Generation mechanism and development characteristics of rail corrugation of Cologne Egg fastener track in metro," KSCE Journal of Civil Engineering, vol. 24, no. 6, pp. 1763-1774, 2020.

[32] J. Piotrowski and W. Kik, "A simplified model of wheel/rail contact mechanics for non-Hertzian problems and its application in rail vehicle dynamic simulations," Vehicle System Dynamics, vol. 46, no. 1-2, pp. 27-48, 2008.

[33] P. A. Bellette, P. A. Meehan, and W. J. T. Daniel, "Effects of variable pass speed on wear-type corrugation growth," Journal of Sound and Vibration, vol. 314, no. 3-5, pp. 616-634, 2008.

[34] P. A. Meehan, P. A. Bellette, R. D. Batten, W. J. T. Daniel, and R. J. Horwood, "A case study of wear-type rail corrugation prediction and control using speed variation," Journal of Sound and Vibration, vol. 325, no. 1-2, pp. 85-105, 2009.

[35] R. Enblom and M. Berg, "Simulation of railway wheel profile development due to wear-influence of disc braking and contact environment," Wear, vol. 258, no. 7-8, pp. 1055-1063, 2005.

[36] G. Shen, Railway Vehicle System Dynamics, China Railway Publishing House, Beijing, 2014.
[37] R. W. Radford, "Wheel/rail vertical forces in high-speed railway operation," Journal of Engineering for Industry, vol. 99, no. 4, pp. 849-858, 1977.

[38] S. L. Xu, W. J. Xu, and Y. X. Zhong, "Simulation analysis of wheel rail impact force at rail joint," Journal of Railways, vol. S1, pp. 99-109, 1989.

[39] X. Cui, J. W. Yao, and L. X. Sun, "Analysis on influence of wheel polygon wear on wheel-rail force based on flexible rotating wheelset," Railway Engineering, vol. 59, pp. 140-145, 2019.

[40] X. Cui, J. W. Yao, X. Y. Hu et al., "Rotation effect of flexible wheelset on wheel-rail force in Euler coordinate system," China Railway Science, vol. 40, pp. 120-128, 2019. 